Relations industrielles

Industrial Relations

\title{
Bibliographie des relations du travail au Canada (1940-1967) par Louis-Marie Tremblay, Montréal, Les Presses de l’Université de Montréal, 1969, 243 pages.
}

\section{Gérard Dion}

Volume 25, numéro 1, 1970

URI : https://id.erudit.org/iderudit/028108ar

DOI : https://doi.org/10.7202/028108ar

Aller au sommaire du numéro

Éditeur(s)

Département des relations industrielles de l'Université Laval

ISSN

0034-379X (imprimé)

1703-8138 (numérique)

Découvrir la revue

Citer ce compte rendu

Dion, G. (1970). Compte rendu de [Bibliographie des relations du travail au Canada (1940-1967) par Louis-Marie Tremblay, Montréal, Les Presses de l'Université de Montréal, 1969, 243 pages.] Relations industrielles / Industrial Relations, 25(1), 152-152. https://doi.org/10.7202/028108ar

Tous droits réservés @ Département des relations industrielles de l'Université Laval, 1970
Ce document est protégé par la loi sur le droit d'auteur. L'utilisation des services d'Érudit (y compris la reproduction) est assujettie à sa politique d'utilisation que vous pouvez consulter en ligne.

https://apropos.erudit.org/fr/usagers/politique-dutilisation/ 


\section{RECENSIONS}

Bibliographie des relations du travail au Canada (1940-1967) par Louis-Marie Tremblay, Montréal, Les Presses de l'Université de Montréal, 1969, 243 pages.

Voici un ouvrage destiné à rendre de grands services à tous ceux qui s'intéressent aux relations du travail et particulièrement aux chercheurs. Ils y trouveront un instrument de référence indispensable pour connaître les travaux qui ont été effectués en ce domaine au Canada entre 1940 et 1967 dans les universités et les organismes gouvernementaux.

L'auteur, qui est directeur du Département des relations industrielles de l'Université de Montréal, a relevé 1269 titres tant en français qu'en anglais et les présente avec une brève notice de contenu. Ceux-ci sont classés en cinq grandes catégories (syndicalisme ; relations industrielles ; aspects juridiques ; maind'oeuvres; administration) et vingt-deux sous-catégories. Un index des sujets et un index des auteurs facilitent la consultation.

A la lecture de ces titres, on ne peut s'empêcher d'être étonné par la multitude des études qui ont été faites, même si l'on sait qu'elles ne sont pas toutes d'égale valeur.

S'ajoutant à l'ouvrage de Ibester, Coates, Williams, Industrial and Labour Relations in Canada: A Selected Bibliography, Queen's University, 1965, ainsi qu'à l'Index cumulatif (1945-1963) déjà publié par Relations industrielles, vol. 18 (1963), no 4. - une nouvelle édition paraîtra à la fin de 1970, - Bibliographie des relations du travail au Canada apporte ici une véritable contribution au développement de la recherche scientifique dans un domaine où il $\mathrm{y}$ a encore beaucoup à faire. L'auteur mérite toutes nos félicitations et nos encouragements.

\section{Gérard DION}

Radical Politics and Canadian Labour, par Martin Robin, Kingston, Ontario, Industrial Relations Centre, Queen's University, 1968, 320pp.

Martin Robin présente dans cet ouvrage de près de trois cents pages une étude fouillée des relations qui ont existé au Canada anglais, plus précisérnent en Ontario, dans les Prairies et en Colombie Britannique, entre le mouvement syndical et les partis politiques de tendances plus ou moins radicales au cours de la période 1880-1930.

Dans une quinzaine de chapitres, qui constituent à la fois une tranche assez peu connue de l'histoire politique au Canada et de l'histoire du mouvement ouvrier en autant qu'il s'agit de sa participation à la vie publique, l'auteur décrit la naissance du radicalisme syndical au Canada sous l'inspiration des Chevaliers du Travail dans les derniers vingt ans du XIXe siècle. On peut en retenir que, à peine né, le mouvement syndical s'est intéressé à la chose politique et s'est rendu compte que, pour progresser, il se devait de quelque manière d'influencer les élus du peuple. Mais comment agir ? C'était là le gros point d'interrogation et c'était là aussi que les avis étaient fort partagés. Les uns, bien entendu, préconisaient l'adhésion massive des travailleurs à un parti socialiste véritable, et c'est ainsi que, au tournant du XXe siècle, s'est formé le Parti socialiste du Canada qui s'est passablement enraciné en Colombie Britannique où il a réussi à faire élire un certain nombre de députés dans les comtés composés principalement d'électeurs ouvriers.

L'auteur retrace ensuite les schismes nombreux qui ont suivis où s'opposent les tenants du socialisme doctrinaire et les partisans du travaillisme, pendant que, de son côté, le mouvement syndical oscille entre trois tendances.

Il y a les partisans de l'action directe voulant que les syndicats agissent par leurs propres moyens, en particulier le recours à la grève, pour arriver à leurs fins qui ne sont nulles autres que l'im- 